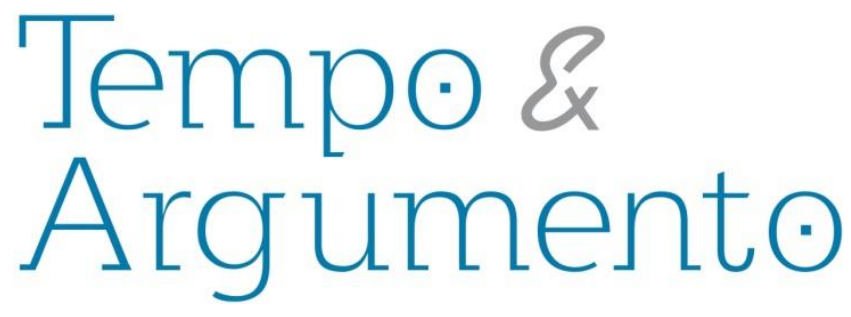

\title{
Memória e testemunho: entre narração e interpretação ${ }^{1}$
}

\begin{abstract}
Resumo
Este texto tem como objetivo apresentar aproximações entre memória e testemunho sob a pressuposição de uma hermenêutica da memória. A discussão tende a relacionar problemas apresentados por Frank Ankersmit e Henri Bergson pela exposição das relações entre representação e simpatia. Para essa finalidade, o texto divide-se em duas partes: a primeira apresenta a constituição da memória como objeto de acordo com o ponto de vista epistemológico e a segunda, a possibilidade relacional entre estética e memória. As duas partes assentarão, no campo da reflexão, diálogos considerando a categoria do passado, no testemunho, ante sua condição de decorrido e ter sido. Aproximar testemunho e memória depende tanto dos princípios narrativos (evocativos), quanto do intérprete (ouvinte).
\end{abstract}

Palavras-chave: Epistemologia da Memória.

Hermenêutica da Memória. Testemunho. Memória.

\section{Rodrigo Tavares Godoi}

Doutor em História pela Universidade Federal de Goiás (UFG). Professor da Universidade Federal de Rondônia (UNIR). Rolim de Moura - RO - Brasil htrtgodoi@yahoo.com.br

\section{Para citar este artigo:}

GODOI, Rodrigo Tavares. Memória e testemunho: entre narração e interpretação. Tempo e Argumento, Florianópolis, v. 10, n. 25, p. 410 - 434, jul./set. 2018.

\section{DOI: $\mathbf{1 0 . 5 9 6 5 / 2 1 7 5 1 8 0 3 1 0 2 5 2 0 1 8 4 1 0}$}

http://dx.doi.org/10.5965/2175180310252018410

\footnotetext{
${ }^{1}$ As proposições deste texto fazem parte de dois projetos de pesquisa, em desenvolvimento, financiados por agências de fomento FAPERO e PIBIC/CNPq com vinculação institucional via PROPESQ. Em ambas as pesquisas, há participação de acadêmicos, bolsistas e voluntários.
} 


\title{
Memory and testimony: between narration and interpretation
}

\begin{abstract}
This text has as objective to present approach between memory and testimony under a presupposition of a hermeneutics of memory. The discussion tends to relate problems presented by Frank Ankersmit and Henri Bergson in the exposure of the relation between representation and sympathy. For this purpose, the text is divided into two parts: the first presents a constitution of memory as the object from the epistemological point of view and the second, for the relational possibility between aesthetics and memory. The two parts shall be based, in the field of reflection, dialogues considering the category of the past, in the testimony, under its condition of elapsed and have been. To approach testimony and memory depends on narrative principles (evocative) how much of the interpreter (listener).
\end{abstract}

Keywords: Epistemology of Memory. Hermeneutics of Memory. Testimony. Memory.

\section{Contingência, representação, duração}

As afirmações deste texto são provisórias. São assim consideradas porque elas compõem pesquisas, em andamento, dedicadas a conceber uma hermenêutica da memória em particular. A atenção volta-se à compreensão da memória e do testemunho por apresentar o passado como representação e autorreferente. Nesse sentido, a discussão acerca da estética ocupar-se-á exclusivamente da não validação do conceito de distância histórica para raciocinar contextos inerentes aos testemunhos (oralidade). Nesse caso, o objetivo não é formular um problema entre memória e estética, mas conceber aproximação de ambas. Para essa problematização, Ankersmit e Bergson são dois intelectuais fundamentais. Sendo ambos importantes neste momento, já partimos de considerações para as quais memória mantém relação direta com o imediato a partir da suspeição entre acontecimento e decorrido. As páginas seguintes comprometem-se 
com a ideia de: quando se trata de epistemologia, há fragilidade na colocação da memória como problema na pesquisa historiográfica² ${ }^{2}$

Pela contingência, presta-se atenção à representação da memória. Enquanto o narrador não diferencia decorrido e evocação, pelo apoiar-se no seu passado, essa contingência faz parte da interpretação que coloca, sob a negação, a alienação temporal retrospectiva. Estando ou não consciente da recusa à contingência, através dela abrem-se duas condições em relação ao acontecimento: discurso e arte. No discurso, o passado evocado compreende-se como idiossincrático. Pela diferença entre o passado em si e representação, a interpretação distancia decorrido e evocação. Na arte, o passado evocado coloca-se face a face ao presente, pois não há distância histórica. A diferença entre passado em si e representação é descartada porque o passado é parte da representação (o espaço torna-se metáfora).

A contingência não deve ser concebida sob a crença externa e causa. Ela não está para a memória como incisão cirúrgica, essa contingência é parte inerente da própria compreensão do testemunho. Marcar os pontos de tensão da pessoalidade produz introjeção na relação simpática entre narrador e ouvinte. Há, neste raciocínio, a constatação teórica do misto, acontecimento e memória. A epistemologia demarca no testemunho a tensão do eu, de sua idiossincrasia e a exigência coletiva da memória. $\mathrm{Na}$ análise, o historiador tende a aderir ao conceito de representação ou discurso. As deliberações subjetivas são manifestas e exigências estabelecidas diante do contexto. Neste caso, há complexidade entre acontecimento, memória e contingência.

\footnotetext{
${ }^{2}$ A ideia de fragilidade para o estudo da memória concentra-se na concepção de temporalidade. Significa afirmar que há desconsideração de elementos temporais não sucessivos (consequências lineares). A fragilidade inerente à epistemologia decorre do fato de a temporalidade ser mantida por conexões analíticas objetivas. A análise predispõe à anterioridade temporal a retenção ou o retroagir, já que o acontecimento possui afinidade com o decorrido. Deste modo, o pensamento epistemológico distancia estética e memória na narrativa evocativa. Segundo Ankersmit (2004, p. 201), a epistemologia não consegue apreender aquilo que é inerente à representação. Sob o crivo da epistemologia, não se pode compreender a indeterminação como parte da representação. A estética é, para Ankersmit, mais adequada que a análise epistemológica porque retira a necessidade de reprodução do passado por buscar sua realidade ou referência. Sob a epistemologia, a história convive com o fantasma da ficção. Sob um ponto de vista, a ficção não se relaciona à existência do que representa (ANKERSMIT, 2004, p. 203).
} 
Sob o ponto de vista da história epistemológica, a contingência implica na ruptura da continuidade e marca a percepção do singular em contextos determinados. Sob o ponto de vista hermenêutico do testemunho, essa contingência não pode ser preconcebida como exterioridade. Neste caso, o testemunho faz acontecer memória e contingência como parte dele, nem causa e nem efeito. Será isso possível? A contingência faz parte das relações de evidência e indício ${ }^{3}$. Também, por considerá-la importante para reflexão no testemunho, a ideia de simpatia corporifica o argumento hermenêutico. A contingência não causa, mas é condição do testemunho.

Atentando-se para a duração simpática, considera-se a différence ${ }^{4}$. Raciocinar acerca dela depende das considerações que circundam evidência e indício. Neste caso, enquanto, por pessoalidade, o testemunho resiste à contingência; por compreensão, o ouvinte demonstra campo de referência e temporalidade. Em outras palavras, a contingência e o acontecimento estão compreendidos na condição de representação tanto quanto na de duração. E o princípio da representação não epistemológica é salutar para a defesa do testemunho congregar elementos estéticos.

Pela condição hermenêutica da memória, sua abordagem temporal reserva-se no direito de: as imagens inerentes ao testemunho tornam-se seu próprio objeto e são verdadeiras, pois agarram-se à psicobiologia. Há uma peculiaridade: o temporal, como evidência e indício, apresenta-se por autonomia e condicionamento. Isso porque o testemunho manifesta-se entre a imagem como evidência e o espaço como indício. Nestes termos, pensar a epistemologia da memória como representação e a hermenêutica dos fenômenos da memória implica diretamente no debate da predicação testemunhal.

\footnotetext{
${ }^{3}$ Evidência e indício são dois termos importantes e fundamentais para raciocinar a aproximação de estética e memória. Aos indícios, argumentos de cunho analítico passam a fazer parte da discussão assim como o de contextos. Mas, neste caso em especial, este texto não conseguirá avançar no debate inerente aos contextos. Para isso, seria necessário adentrar a duas questões fundamentais: arqueologia e retórica. Às evidências, há necessidade de se concentrar nos conceitos de estética e imagens-lembrança. A evidência deixa de ser compreendida como prova material analisada e passa para autorreferente.

${ }^{4}$ Nesse caso, différence deve ser compreendida como misto de grau e natureza distintos. A différence concentra-se na interpretação do grau e da natureza no misto a fim de demonstrar movimento e trajetória na memória como duração. Como princípio hermenêutico bergsoniano, a différence compreende o passado em seu dualismo de parada e prolongamento, representação e ação, atualização e virtualidade, utilidade presente e autorreferência.
} 


\section{O passado em si e o problema da representação}

Enquanto próprio e não distante, o passado está assimetricamente apreendido em estruturas, elas são diacrônicas. São estruturais circunstâncias não organizadas segundo sucessão de eventos passados, sua duração prolonga-se mediante estabilidade (KOSELLECK, 2006, p. 135, 137). Também, considera-se a imprescindível relação entre memória e estrutura. O imediato pode ser compreendido como metaconceito ou conceito. Neste caso, o conceito é pertinente para a discussão entre metáfora e imanência. Sendo essa imanência hermenêutica, o ponto de vista significativo da relação direta entre memória e contextos apreendidos por analítica, retira da memória sua propriedade biológica das inscrições 5 .

A relação entre memória e estrutura compreende a diacronia sendo o imediato e a duração partes da própria estrutura. As circunstâncias inerentes à estrutura não cooptam a contingência na condição externa. Compreendendo o princípio estético, na memória a estrutura dependerá do esquema não controlado pelo narrador a partir da relação entre conteúdo, conceito, tema, expiração do passado. Diferentes da historiografia, o contexto e o acontecimento apreendem-se à circunstância sincrônica entre duração e deliberação de motivos. Nesse ponto, a atenção volta-se para a dimensão entre presente e presença, corte não epistemológico e significação, atualização e síntese. Inegavelmente, para a narração da memória, o acontecimento fica inerente ao testemunho, a circunstância torna-se o próprio corte não epistemológico e a contingência demanda campo de referência entre narrador e ouvinte. Não se pode esquecer que, para Bergson (1991, p. 113), o corpo é um sistema fechado.

\footnotetext{
${ }^{5}$ Neste ponto importa reconsiderar a discussão de Maurice Halbwachs (contrário ao bergsonismo). Mas, a atenção não é necessariamente à crítica e sim ao pressuposto. Em Halbwachs, o conceito de memória coletiva retira o individual da memória e a coloca em coisas ou quadros. Pela perspectiva estruturalista da linguagem, o campo simbólico é factível. O corpo, neste momento, desempenha papel secundário. A partir de um raciocínio epistemológico aplicado à psicologia, compreende-se a memória no campo social porque sua relação estrita ao indivíduo a inviabiliza. A análise da memória depende dela manifestar-se ou ser apreendida historicamente pela abordagem contextual. Na consideração de Jan Assmann (2000, p. 35-37), leitor de Halbwachs, esses quadros são determinados pela cultura como estrutura imediata na qual sua inscrição não depende de associações ou articulações racionais. A função comunicativa da memória determina sua condição coletiva.
} 
Na recusa funcionalista da memória, o estudo diante das tematizações diversas que se possam realizar em torno dela, o caráter compreensivo de sua relação com o acontecimento e a contingência, minimizam o determinismo existente no armazenamento e no hábito. Não pertence ao esforço e nem ao lembrete, mas à propriedade temporal compreendida se concebido o passado em si. Por esse motivo, a representação entra no centro da discussão devido ao fato de Bergson (1991, p. 115, 117) pensá-la distinta da ação.

De maneira não diacrônica, a circunstância passa a ser entendida sob a tensão entre referência e representação. Sua finalidade é demarcar a distância do passado, pois a narração da estória depende dos mythoi (WHITE, 2001, p. 77). Como representação, o mediato estabelece o acontecimento ligado ao decorrido em simetria. A distância histórica marca a diferença entre passado e presente. Sua proximidade depende de processos idiossincráticos. Enquanto historiografia, há de se prestar atenção para uma questão fundamental: as estratégias tropológicas das apropriações metafóricas (WHITE, 2001, p. 91).

O contexto histórico da memória depende da relação de apropriação do externo ao corpo (psicobiologia). E, como se trata de pessoalidade, a representação do narrador não coloca limite entre evidência e indício, mesmo ambos sendo limiares. A tendência, pelo fato do não mais, aproxima acontecimento decorrido e memória testemunho. Essa aproximação pode ser vista como alienação. Para o ouvinte, interpretar a dependência idiossincrática torna-se improvável. Seria possível, caso o narrador colocasse a si mesmo como objeto. Pelo contrário, para a interpretação concebe-se a nostalgia inerente ao testemunho ${ }^{6}$. Idiossincrasia e nostalgia ocupam posições distintas na representação. Enquanto a primeira dá ênfase para a vivência (biologia), a segunda ocupa-se com a experiência sublime.

\footnotetext{
${ }^{6}$ A nostalgia dá a experiência mais intensa e autêntica do passado. A experiência transindividual não compreende a experiência nostálgica. É como se a nostalgia unisse passado e presente; o passado deve ser sempre experimentado de forma pessoal. Neste caso, a consideração de evidência e prova não faz parte da nostalgia. Nostalgia e recordação estão paralelas, pois se trata de sentimento e não de alguma coisa. Comparou recordar com recordar que, significa que o segundo está para o sinônimo de saber que. Sua aproximação com o recordar está no fato de necessitar do passado como experiência (ANKERSMIT, 2012, p. 381, 385-394). Com esta perspectiva, é possível relacionar a visão de Ankersmit e Halbwachs. Em sua teoria da representação histórica, a memória incorpora-se, mesmo pessoalmente, ao coletivo privativo. Assim, o passado pessoal, como recordação (nostalgia), ordena-se com um passado coletivo de vários séculos passados (ANKERSMIT, 2012, p. 397).
} 
Sendo nostálgica, não há separação entre representação e referência; seria melhor substituir representado por apresentado. Não há operação de dois, mas três lugares. Neste caso, implica diretamente na discussão sobre significado e linguagem (ANKERSMIT, 2012, p. 194, 197). Sendo a representação questão de três lugares, a nostalgia deixa de fazer menção à distância como descrição exclusiva e passa a apresentar o aspecto (ANKERSMIT, 2012, p. 190, 194). Essa leitura da nostalgia desestabiliza a crença do passado em si, pré-dado ou absoluto.

Até este ponto, defende-se a interpretação da memória, o acontecimento, como lembranças pendulares entre um passado decorrido e um passado evocado. Essa memória marca o testemunho como acontecimento. A narrativa expõe o narrador que compromete e apoia-se nela. Na condição de representação, esse testemunho recoloca o passado no presente a partir de significado ${ }^{7}$. A distância é substituída pelo imediato que estabelece o passado face a face. Na condição hermenêutica (a saber, a différence), o passado coloca-se atualizado porque lembranças marcam paradas e prolongamentos.

A partir da colocação do problema é possível observar que nossa problemática se concentra no fato do acontecimento da memória não se alienar ao decorrido e a contingência não determinar causa. O testemunho e a memória configuram o acontecimento. A temporalidade desvincula-se da experiência analítica dos contextos objetivos bem como não depende de processos idiossincráticos (subjetivos). Para a defesa de tal ideia há a necessidade de articular a possibilidade de aproximar memória, duração e estética. Essa aproximação depende da defesa dos elementos substanciais autorreferentes da memória, ou seja, das imagens-lembrança. Por esse motivo, acontecimento, decorrido e contingência compõem ressignificação diante a historiografia. A contingência possibilita ao acontecimento sua relação com a exigência de um passado em si e sua atualização independente do decorrido. Pensar a ressignificação dos termos apresentados demanda considerações entre epistemologia e filosofia da memória. Assim, as duas partes seguintes cumprem a função de apresentar os fundamentos pretendidos neste texto.

7 O significado depende da certeza do sentido do passado e sua presença. Esse passado é inerente ao testemunho na condição de inscrição e partilha. O passado testemunhado compromete-se com sentimentos do passado presente e determinação contextual das relações descritas. 


\section{Memória e Epistemologia}

(...) o passado não tem rosto, e as máscaras que fazem os historiadores são tudo o que temos. Assim, tão logo abandonamos a esfera da ação humana intencional, o passado não tem um significado intrínseco, oculto ou de outra classe, e é decididamente estranho falar acerca de interpretar o significado de algo que não tem um significado intrínseco. (ANKERSMIT, 2004, p. 198)

Antes de adentrar diretamente à questão implícita à crítica da epistemologia da história, importa prestar atenção ao conceito de passado. O passado deixa de ser concebido como elaboração subjetiva ou objetiva no trabalho cognitivo do historiador. O passado não pode ser concebido como passivo e nem pode enterrar os vivos.

O passado como verdade e o passado como significado são coisas diferentes, segundo Ankersmit, no pensamento epistemológico e na hermenêutica analítica. $O$ passado inerente ao significado produz especulação, já o significado está menos presente no passado do que sugere normalmente a hermenêutica. Assim, não tendo um significado intrínseco, não se pode interpretá-lo. O significado ligado a um objeto se aproxima da loucura metafísica (ANKERSMIT, 2004, p. 197, 198).

Nestes termos, Ankersmit (2004, p. 200, 201) propôs a aproximação entre filosofia da história e estética, uma vez que, para ele, a representação é mais dotada de explicação do que o vocabulário da descrição e explicação, significado e objeto. A representação não necessita que o passado tenha um significado ${ }^{8}$. No caso do testemunho (evocação), passado e presente estão ainda mais próximos do que um passado distante.

Ankersmit demonstra uma ideia de história manifestadamente contrária à perspectiva epistemológica. A concepção de real nesse historiador denuncia a tradicional escrita da história. Realidade, contexto histórico, passado e objetividade não fazem referência à ideia de distância. Pelo pensamento epistemológico, o passado mantém-se

\footnotetext{
${ }^{8}$ Para não gerar mal entendido, Ankersmit (2004, p. 371) rejeita o raciocínio da intenção na ação humana, inerente à perspectiva hermenêutica; a explicação por descrição, da epistemologia científica e, ainda, o pensamento pós-moderno pelo abandono do conceito de representação devido à falta de profundidade ao tentar separar realidade de linguagem. A expressão o passado é um texto iguala duas coisas diferentes. A noção de texto significado apresenta uma contrariedade, acreditar que sempre há algo fora do texto (ANKERSMIT, 2004, p. 200). A aproximação ao pensamento estético preserva, para Ankersmit, argumentos que contrariam as defesas hermenêuticas e epistemológicas.
} 
distante do presente, problema aparentemente resolvido pelo historiador. Aparente porque presume ser na narrativa, como escrita histórica, a condição equilibradora das distâncias e estabelecedora das pontes (ANKERSMIT, 2001, p. 155).

A escrita histórica moderna possuiu como atributo criar conceitos e racionalizar o passado a partir de sua realidade histórica. Pela narrativa historiadora, as relações com o passado tornavam-se possíveis se, e somente se, esse passado fosse apresentado objetivamente. $\mathrm{O}$ critério da objetividade histórica presume a distância entre passado e presente resolvida no trabalho cognitivo do historiador. Ankersmit fez uso do termo transindividual para descrever a crença manifesta na escrita histórica, especialmente na época da disciplinarização da história ${ }^{9}$, marcada, entre os séculos XIX e XX, pela convicção do passado independente do historiador. Desta forma, as interpretações puderam ser comparadas, criticadas e julgadas (ANKERSMIT, 2001, p. 150).

For if there is a background enabling us to define the merits and shortcomings of individual historical interpretations, this background also enables us to establish where each historical interpretation has significantly contributed to our knowledge of the past. (ANKERSMIT, 2001, p. 151 $)^{10}$

O termo pontes foi usado por Ankersmit (2001, p. 155) para representar um paradoxo: a escrita da história torna-se a possibilidade de aproximação do passado ao mesmo tempo em que o mantém a distância. Desta forma, as pontes marcam a distância e nos ajudam a superá-las. Por esse ponto de vista, compreende-se em Ankersmit rejeição à perspectiva epistemológica, fundamentalmente em torno da que prega objetividade. Em termos, sua discussão suspende a crença no contexto histórico que estabelece a realidade histórica sob o método da objetividade analítica.

\footnotetext{
${ }^{9}$ A disciplinarização da história pautou-se pela consolidação dos grandes conceitos (Estado, nação, classe social e outros) como maneira de acessar o passado. Chamando-a de história moderna, Ankersmit (2002, p. 150, 155) afirmou ter sido ela a história disciplinar porque retirava de suas representações as atribuições privativas. Ao individual caberia o problema da memória, já, para a história, entraria o problema da coletividade.

${ }^{10}$ Pois se há um fundo nos permitindo definir os méritos e deficiências de interpretações históricas e individuais, este fundo também nos permite estabelecer onde cada interpretação histórica tem significativamente contribuído com nosso conhecimento do passado (tradução livre do autor).
} 
Esse posicionamento não é estranho, pois repetidas vezes, em seus textos ${ }^{11}$, questiona tanto a epistemologia quanto a hermenêutica. No caso da segunda, protelarei a crítica. Mas, em relação à primeira, é importante constar a evidência de o passado não estar a uma distância segura a ponto de não se confundir com o presente, marcando claramente suas bordas pelo esforço do historiador.

Ankersmit recoloca a questão da memória como a responsável pela insuficiência epistemológica da história. Com Ankersmit há ressignificação da história e memória na sua teoria da representação histórica. Mas, parece haver uma encruzilhada mal resolvida quando se pensa a partir desse autor. Sob a teoria da representação, o passado perde suas relações estritas com o decorrido e o contexto. A encruzilhada referida está entre a defesa de um passado ausente de distância e um passado em si. Por esse motivo é preciso apresentar com mais cuidado os termos significativos.

Àprimeira vista, pode aparentar que há um pensamento epistemológico e outro da representação. O epistemológico, defensor da referência para além do texto, e o da representação, como crítico à ideia de distância. Mas o que não se pode esquecer é o fato de haver, neste texto, a consideração de uma hermenêutica da memória em particular. A representação sustenta a inexistência de um passado em si, o que não se aplica à hermenêutica.

O problema epistemológico na representação decorre da crença na anterioridade como significado podendo ser reconstruído pelo historiador. Em Ankersmit, essa crença faz parte da distância. Por ela, a historiografia convenceu-se de as fontes agregarem ou apontarem para contextos objetivos. Ao historiador, o trabalho cognitivo responde às demandas inerentes por apresentar ao público leitor um algo para além de suas possibilidades cotidianas: o passado.

Nos termos de Ankersmit, a ingenuidade da historiografia do século XIX e XX foi a de não problematizar, não propriamente o conceito, mas a teoria da representação. Consequência de uma escrita da história (moderna) apegada à simetria temporal dos contextos. Definitivamente, a partir de Ankersmit, a perspectiva de uma hermenêutica da

\footnotetext{
${ }^{11}$ Neste caso, refiro-me às obras Historia y Tropologia (2004), Escrita da História (2012) e Historical Representation (2001).
} 
memória considera frágil o pensamento epistemológico como tematização da memória. Mesmo assim, também seria ingenuidade acreditar que a teoria da representação histórica é empática a hermenêutica. Como exemplo, o autor criticou a hermenêutica filosófica de Hans-Georg Gadamer porque as pontes se fazem sob o regime do sentido. Ou seja, a tensão está para a relação entre representação e demonstração, significado e sentido, tema e atualização.

Para começar, Ankersmit aproximou-se da filosofia da história para ultrapassar os critérios epistemológicos da representação condicionados nas leituras pós-modernas ${ }^{12}$. Por esse motivo, o problema da memória na escrita da história complica-se quanto ao concebido como passado e, como ele, age no testemunho.

Para adentrar ao estado de tensão entre representação e hermenêutica, permanecemos no diálogo sugerido por Ankersmit. É com base na filosofia, que a ideia será a de apresentar considerações de Bergson em torno da estética. Dispensando a tradicional contextualização do autor e do seu pensamento, constata-se o fato dele não ter escrito nenhuma obra específica de história ou para historiadores. Mas isso não impediu a contribuição de seu pensamento para o trabalho dos historiadores, principalmente nesse momento de incertezas à tradicional historiografia da memória. ${ }^{13}$

A nosso ver, é importante prestar atenção para a consideração introdutória de Bergson à estética e, a partir daí, compreender porque a concepção de hermenêutica da memória, neste momento, aproxima-se mais do bergsonismo do que da representação. Para esse fim, necessita-se pensar em duração.

Bergson, com sua filosofia da metafísica imanente, fez, sob o ponto de vista de sua filosofia da memória, crítica ao pensamento epistemológico. Para ele, a tradicional separação entre objeto e sujeito determinada pela análise, colocava em vertentes

\footnotetext{
${ }^{12}$ Neste ponto, especificamente em relação ao texto Representación histórica, Ankersmit (2004, p. 199) aproximou Hayden White de Paul Ricoeur por terem colocado o passado como texto perfazendo a ideia de um texto significado.

${ }^{13}$ Neste texto, considera-se tradicional historiografia da memória aquela que coloca a memória como sujeito ou objeto partindo de princípios epistemológicos a partir do conceito de representação, discurso ou analítica de contextos históricos. Racionalizar memória pela orientação subjetiva ou objetiva fratura o potencial da memória ser interpretada à luz de fenômenos mnésicos. Por esse motivo, nossa porta de entrada está sendo com Ankersmit, na qual há crítica à estrutura epistemológica de pensamento. Tematizar memória, depende de compreender o tempo não simétrico, da suspeição do conceito de distância e da determinação idiossincrática.
} 
opostas aquilo que deveria, por simpatia intelectual, aproximar, coincidir, intuir. O objeto não é passivo, dado ou distante. Para Bergson (1957, p. 135), o corpo é um objeto como os outros e neste sentido, o objeto possui a referência da causa. Aponta-se para a possibilidade da não passividade do objeto e para a não determinação do sujeito.

Deste modo, a memória fica entre sujeito e objeto em relação positiva. Não é complementar, mas simultânea, coincidente, simpática. Se a memória for concebida por simpatia, nela mesma, não haveria problema, mas essa simpatia remete ao testemunho. Testemunhar leva em consideração o ouvinte, a partilha, o campo referencial. Neste caso, a interpretação precisa demonstrar o esforço simpático do narrador a fim de evitar determinismo interpretativo do ouvinte.

Nas observações de Taki Ichiro (1997, p. 17), pensar a estética de Bergson incide diretamente na consideração da duração e da intuição. Esta última como base para pensar estética porque fundamenta tanto arte e filosofia, assim como possibilita a junção entre metafísica e ciência ${ }^{14}$. Duração e intuição não se separam no pensamento de Bergson, ou seja, para se compreender a duração presume-se a intuição. Nestes termos, a duração se comporta no bergsonismo como objeto e a intuição como método. Na carta escrita a Höffding, Bergson afirmou que, para abordar a intuição, se pensa em duração (ICHIRO, 1997, p. 19, 20).

Nous pouvons donc dire que la durée précède l'intuition quand on voit la philosophie de Bergson" du dehors", tandis que celle-là coexiste avec celle-ci quand on la voit" du dedans". Il est maintenant possible de supposer qu'il y a toujours une relation étroite entre les deux termes dans toute la démarche philosophique de Bergson, non pas au niveau de ses écrits et de ses paroles mais au niveau de sa pensée. Reste à éclairer, en suivant néanmoins les textes de Bergson, la structure et la fonction de l'intuition bergsonienne pour savoir somment celle-ci implique en ellemême la durée. (ICHIRO, 1997, p. 20) ${ }^{15}$

\footnotetext{
${ }^{14}$ É importante não confundir o termo ciência com ciências representativas. O vocabulário bergsoniano é específico neste caso. A compreensão de ciência está no fato de, baseado nos argumentos de Ichiro, Bergson ter desejado consolidar a metafísica como ciência. Deste modo, para consideração da metafísica como ciência positiva, havia a necessidade de definir objeto e método para essa ciência do tempo.

${ }^{15}$ Podemos, portanto, dizer que a duração precede a intuição quando se vê a filosofia de Bergson de fora, ao passo que aquela coexiste com esta, quando vista de dentro. É possível supor que há sempre relação estreita entre os dois termos em todo desenvolvimento filosófico de Bergson, não ao nível de seus escritos e de suas palavras, mas ao nível de seu pensamento. Resta esclarecer, seguindo os textos de Bergson, a estrutura e a função da intuição bergsoniana para saber que o cimo desta implica a duração (tradução livre do autor).
} 
Duas implicações importantes da citação acima: 1. O bergsonismo não pensa em sistemas de oposição (ser/não-ser, lógico/caótico, vida/não-vida); 2. Sem intuição não há simpatia intelectual à duração. São realmente implicações de base teórica que interferem diretamente na memória-objeto.

A intuição como simpatia intelectual, compreende ou desenha a duração sob os critérios que perpassam a discussão estética. Neste ponto, não se questiona a postura de considerar desnecessária a aproximação entre Ankersmit e Bergson. Ambos estão, sob a estrutura do pensamento e dos argumentos, dispostos a recusar a distância entre passado e presente por incluir o conceito de imediato ${ }^{16}$. O imediato rompe e questiona a epistemologia não com base na ingenuidade; pelo contrário, a crítica à distância como defesa analítica procede por princípios não deterministas. O pensamento artístico tematiza, a experiência estética perde o peso do contexto (decorrido). A arte, por ser estética, descontextualiza e recontextualiza (ANKERSMIT, 2001, p. 167).

A crítica estética a distância, descrita por Ankersmit, envolve o intervalo entre recordar e recordar que. A coexistência entre du dehors e du dedans no pensamento de Bergson constitui o valor da différence, devido à coincidência entre imagens e objetos. E considerando a simpatia como interpretação, designa-se a ela a intenção de compreender o objeto no seu interior. Essa compreensão é descrita por Bergson como o coincidir com aquilo que o objeto tem de único e inexprimível. Mesmo na aproximação entre Ankersmit e Bergson, não se pode esquecer que estética e imediato não possuem a mesma significação para ambos. Mesmo sob o risco anacrônico, essa aproximação assinala mais para a condição da representação do que, propriamente, para distinção entre presente e presença.

A análise consiste em exprimir uma coisa em função do que ela não é. Essas considerações, a partir de Ichiro, estimulam conceber o raciocínio bergsoniano pelo descredenciamento da análise porque ela faz a confusão de determinar uma coisa por outra. Se tomar o corpo como objeto, o que se apresenta como dentro é a memória que

\footnotetext{
${ }^{16}$ No caso de Bergson, essa relação intrínseca e simultânea entre passado e presente está tão clara que para ele, a discussão não se funda, necessariamente, entre passado e presente, mas entre ele e o que sucede (avenir).
} 

corpo não é nem pura imagem e nem pura matéria.

Essa conclusão de Bergson decorre do fato de que se o corpo for pura imagem, ele não consegue devolver o que recolhe. Também não pode ser pura matéria porque a matéria não se limita a ele; o atravessa e o ultrapassa. Nessa medida, sob o princípio cartesiano, há duas linhas, vertical e horizontal que ligam e coincidem pontos para traçar um plano. Ainda, o corpo como exata proporção não nega nem a tendência para análise e nem as imagens puras.

A negação de Bergson (1957, p. 132) foi submeter estética à analítica. Analisar causalmente é uma tendência ou hábito assim como o de respirar; forma análoga é a busca de contextos. Ou como diz Ankersmit, "The human mind is associative and feels an irresistible need to connect, to associative and to contextualize" (ANKERSMIT, 2001, p. $166)^{17}$.

Compreende-se haver em Ankersmit e Bergson a ideia de que, em se tratando de estética e memória, o imediato rompe com os contextos. Mas, para Bergson, eles não podem ser considerados privatização do passado - base da argumentação de Ankersmit. Bergson (1957, p. 130) criticou a postura analítica quanto ao sempre estar considerando a causalidade pelo critério do antecedente ou sistema de antecedentes determinados. Há, nestes critérios da psicologia, que se condicionar o interno ao molde externo.

Neste argumento da psicologia, a ideia de causalidade baseia-se pelo sensóriomotor ou hábito motriz, ou seja, causa e efeito baseiam-se na relação entre visual e tátil mediante progressões impressas (BERGSON, 1957, p. 134). Desta maneia, as impressões progressivas do sistema sensório-motor designam a carência ao necessário, designação que imprime a impressão (sensação) do relacional entre o que vem antes e depois. A causa decorre da análise quando substituído o imprevisto pela regularidade e a liberdade pela necessidade. A causa precede o efeito, assemelha-se à força do agir que,

\footnotetext{
17 A mente humana é associativa e sente uma necessidade irresistível de conectar, de associar e de contextualizar (tradução livre do autor).
} 

causa e efeito. O relacional da causalidade está entre princípio e consequência, duas variáveis funcionais entre si.

A versão analítica da causalidade implica a necessidade rigorosa (BERGSON, 1957, p. 135, 136). Esta discussão de causalidade em Bergson está apresentada também na obra La Pensée et le Mouvant. Nela, o autor deixou evidente seu posicionamento em relação à causalidade psíquica. Em suas considerações, causa e efeito rompem, na memória, a posição de anterioridade. Dito de outra maneira, não se pode compreender a memóriaacontecimento mediante a determinação idiossincrática ou contextual. Isso significa haver, em Bergson, rejeição à perspectiva da distância na memória.

Para constituir memória em objeto é necessário inclinação para a psicobiologia. 0 corpo não pode ser considerado secundário, ao contrário, sem o considerar, a memória não tem nenhuma função social e individual. Diferentemente das prerrogativas defendidas no pensamento de Halbwachs, inerentes aos argumentos de Ankersmit, a filosofia da memória em Bergson não colocou em oposição social e individual. Aliás, nem poderia, uma vez que a memória, em relação aos dois, não pode ser atribuída a elementos motrizes da psicologia e nem a determinações representativas simbólicas.

O ponto fundamental de Bergson estreita-se na definição da memória por fenômenos e não idiossincrasias ou aspectos. Conceber a memória sob o critério de fenômeno retira o argumento, equivocado de Halbwachs, ao afirmar ter sido Bergson defensor de uma memória individual. Os questionamentos de Bergson criticaram a psicologia epistemológica. Pensar na possibilidade relacional entre estética e duração fundamenta o argumento que rompe com os ataques ao bergsonismo decorrentes da influência de Halbwachs.

Na base filosófica, Bergson (2012, p. 50) separou belo de agradável. O segundo está para a sensibilidade e o primeiro para a inteligência. Mesmo assim, levando em consideração a discussão do autor no Données Immediates sobre os intervalos e 

princípio de trabalho intelectual.

O belo apresenta a relação com o fim. Na obra de arte, ela produz em si, seu encerramento, sua finalidade (BERGSON, 2012, p. 50, 51). Motivo pelo qual, não se necessita recompor contextos. Nesse caso, o historiador não possui a tarefa de perseguir o lugar social de sua elaboração. A arte possui relação maior com a criação e liberdade que são necessariamente contextos e precedências influenciáveis. O critério da análise perde qualquer exigência sobre a arte naquilo que tange a confiabilidade, exatidão ou validade. A arte não pode ser problematizada sob a luz de lugares que ultrapassam sua temática. Mesmo assim, em Bergson a arte não pode ser completamente dissociada da moral. A moral na arte implica nela o princípio do ensinamento. $O$ espectador não possui necessariamente postura individual e subjetivista, mas há em sua temática elementos que ultrapassam as individualidades (processo decorrente dos intervalos). Por ser relacional, o objetivo da arte não é o de produzir o senso de bonito ou feio, mesmo esses elementos estando próximos dela. Desse modo, Bergson (2012, p. 52) considerou insípida a relação entre moral e arte.

Ainda, na dimensão da verdade e do belo, a primeira tem característica universal influência de Aristóteles -, a segunda encarna-se por sensibilidade e acessibilidade aos sentidos. O belo não possui relação com obrigação sensível, utilidade e ato obrigatório. $O$ belo esbarra na tipificação ideal. O belo nunca é um objeto em si mesmo, mas a ideia profunda em que um juízo se compara ao ideal concebido por cada um (BERGSON, 2012, p. 52-54). Ainda assim, como se trata de consideração fenomenal, Bergson acreditava ser essa tipificação ideal na mente oriunda de um termo nascido da experiência. Esse tipo ideal "expresa lo más profundamente real en el género al que el individuo pertence" (BERGSON, 2012, p. 55) ${ }^{18}$.

\footnotetext{
${ }^{18}$ Expressa o mais profundamente real no gênero ao qual o indivíduo pertence (tradução livre do autor).
} 
Em outras palavras, a filosofia bergsoniana aproximou de suas discussões referentes ao belo o que se tem por sensibilidade, tipificação ideal e, ainda, termos como gêneros decorrentes da experiência. A filosofia bergsoniana não compreende a experiência a partir de abstrações, pelo contrário, a experiência deve ser a base real, vivencial, experimental, cujas manifestações de emoções, sensações e sentimentos se expressam sem que a arte se torne pueril. A experiência evidencia a memória nas suas relações de intermediários e de intervalos. Para este fim, Bergson considerou o fator negativo de conceber o belo sob o ponto de vista do instinto e da ficção.

Como conclusão desta parte, pode-se afirmar que a estética e memória presumem rejeição ao conceito de distância. O imediato somente é pertinente para a memória se ela se aproximar da estética. O argumento estético leva a considerar duas coisas: a memória não se limita ao tempo biológico individual e o passado desprende-se de contextos decorridos.

O significado do passado não se encontra fora da pessoalidade manifesta continuamente no presente. Com isso, pode-se designar a competência estética da memória desgarrada do peso do passado pelo decorrido. Mas constatar que a estética recusa a espacialidade ausente temporalmente, não aproxima teoricamente Ankersmit e Bergson justamente pelas considerações em relação ao imediato.

\section{O passado imediato}

Retomando uma discussão de Ankersmit, pode-se afirmar que ele demonstrou interesse pelo passado imediato e, a partir de Halbwachs, apresentou o conceito de privatização do passado. Essa privatização não poderia ser descrita como individual ou de experiência por vivência, uma vez que, o passado, mesmo longínquo, liga-se imediatamente ao indivíduo do presente. Essa democratização do passado e, como consequência, a desdisciplinarização da história, recoloca no centro o problema da memória e da história.

Em seus termos, a privatização do passado altera a tradicional visão da memória como lembrança do passado pessoal individual e da história como passado coletivo. 
Ankersmit (2001, p. 154) defende que a memória remonta para o rejeitado da história. A memória foi marginalizada, na história moderna, segundo ele, porque do passado o que interessava pertencia a tópicos de coletividade (nacional, social ou econômico). Rompendo com o conceito de distância, no mundo pós-moderno, segundo Ankersmit, há colocação face a face com o passado. Esse passado passa a ser mais concreto e, ao mesmo tempo, mais estranho.

Falando de Bergson, Ankersmit atestou ser ele defensor de uma memória orientada pela durée. Cada indivíduo possui em si a duração de estados mentais.

It is the individual's memory of such recurring phenomena that serves as the basis for the notion of intersubjective time in which the collectivity orders its history In general, not reality itself, but the memory of individual human beings (and similarities in these memories) is the ultimate source of our knowledge of such recurring phenomena. And thus we cannot avoid the conclusion that the individual's memory is the ultimate basis for collective memory and not the reverse. (ANKERSMIT, 2001, p. 156 $)^{19}$

A rejeição de Halbwachs em relação ao raciocínio de Bergson concentra-se no fato dele afirmar: "First of all, for our memories to be accessible to us at all, we have to be able to put them into words, and since language and the meaning of words are socially determined, the same must be said about memory" (ANKERSMIT, 2001, p. 156) ${ }^{20}$. Para Halbwachs, a memória é mais do que descrição pura, ela é construção que precisa de categorias sociais e coletivas estruturadoras do mundo e da comunicação. Não há memória solipsista individual, pura, da percepção. A memória é sempre codeterminada pelas categorias sociais que determinam a seleção e a comunicação.

Inspirado em Halbwachs, Ankersmit afirmou ser a crença na concretude de uma memória individual, falsa. A vida do indivíduo é uma interação com as forças sociais,

\footnotetext{
${ }^{19}$ É a memória do indivíduo, de certo fenômeno recorrente, que serve como base para a noção de tempo intersubjetivo ao qual a coletividade determina sua história. Em geral, não a realidade em si, mas a memória do ser humano individual (e similaridade nestas memórias) é a fonte final de nosso conhecimento de certo fenômeno recorrente. E assim, não podemos evitar a conclusão de que a memória do indivíduo é a base final para a memória coletiva e não o reverso (tradução livre do autor).

${ }^{20}$ Primeiro de tudo, para nossas memórias serem acessíveis a nós, temos de ser capazes de colocá-las em palavras, e depois a linguagem e o significado das palavras são socialmente determinados, o mesmo deve ser dito à memória (tradução livre do autor).
} 
miríade constituinte da coletividade. Nesse ponto, faz uma observação: "Not society, but the individual is an abstraction" (ANKERSMIT, 2001, p. 157) ${ }^{21}$. Sob o critério do inconsciente, a maioria das manifestações sociais não se liga diretamente ao consciente, por isso há determinação do meio (UmWelt). "Collective memory is most powerful precisely where we most sincerely believe to be in an unmediated, pure contact with our innersmost self and our most private past" (ANKERSMIT, 2001, p. 157) 22.

O convencimento de Ankersmit é tão certo que, para ele, o uso do adjetivo coletivo para se referir à memória é redundante. Ao invés de adjetivação, o coletivo da memória compõe sua substancialidade. Seu elogio a Halbwachs decorre do fato de que, para Ankersmit, o conceito de memória coletiva rompe com a história tradicional. A partir dele, passou-se a ter acesso direto ao passado sem necessitar de conceitos históricos que o colocam à distância.

Ao contrário, a defesa de Bergson foi a da memória, pela intuição, não ultrapassar os limites da vida individual. A coletivização da memória permite a possibilidade de a memória individual acessar o passado histórico da sociedade da qual cada um faz parte. Não há mais barreiras entre o passado pessoal e coletivo. A anterioridade da própria vida biológica passa a fazer parte das lembranças pessoais. A tese de Halbwachs foi de a história ser profunda na mente dos seres humanos individuais (ANKERSMIT, 2001, p. 157, 158).

Nas considerações de Ankersmit (2001, p. 159, 160), Halbwachs tornou público o que era privado, o individual passou a fazer parte de coisas sociais. A vantagem desse sociólogo foi ter alargado o passado. Sob o preceito da privatização e democratização do passado, Ankersmit expressou: “For as soon as we erase (...) our unquestioned assumptions about what is private and what is public or social, we can both socialize the private and privatize the social" (ANKERSMIT, 2001, p. 160) ${ }^{23}$. A defesa da representação parte do princípio de o passado possuir mais relação com o nostálgico do que

\footnotetext{
${ }^{21}$ Não a sociedade, mas o indivíduo é uma abstração (tradução livre do autor).

${ }^{22}$ A memória coletiva é mais poderosa precisamente quando nós sinceramente acreditamos estar em um contato puro, em mediação com nosso eu mais íntimo e nosso passado mais privatizado (tradução livre do autor).

${ }^{23}$ Pois assim que apagamos (...) o que é particular e o que é público ou social, podemos ambos socializar o privado e privatizar o social (tradução livre do autor).
} 
propriamente com a distância e o individual. Sem incidir em incoerência quanto à teoria da representação histórica de Ankersmit, tematizar a memória não significa que a experiência pessoal deixa de ser importante. Mas o que não tem sentido é a memória ficar enclausurada à percepção individual limitando-se à história de vida biológica.

A função estética do passado agrega à memória o direito de a experiência pessoal ultrapassar seus anos biológicos e adentrar em conteúdos de séculos passados. Pode-se, então, atestar que a validade desse argumento se destina para a crise epistemológica porque o passado perde suas referências rígidas a contextos e cronologias. O tempo deixa de ser contado sob o rigor simétrico da datação e transforma-se em velocidade ou raio infiltrando-se, profundamente, como os conteúdos de história, na memória. Os conceitos e categorias tradicionais são esvaziados da tutela do tempo que aprisiona o passado à distância.

Tempo, passado, história e memória refazem as pazes porque abandonam a perspectiva epistemológica e aproximam-se incondicionalmente da representação. Ankersmit faz uma leitura estética de Halbwachs, retira-o do problema levantado quanto à representação simbólica da memória. Ankersmit (2001, p. 168) afirmou ser a memória artificial quando submetida a lugares ao parafrasear o autor anônimo de Ad herennium. Esse ponto de vista pode ser mais instigante quando Ankersmit fala da testemunha.

Ao tratar do Holocausto, definiu testemunhar a partir de Soshana Felman:

To testify before an audience of speakers or spectators - is more than simply to report a fact or an event or to relate what has been lived, recorded and remembered. Memory is conjured here essentially in order to address another, to impress upon a listener, to appeal to a community... To testify is thus not merely to narrate but to commit oneself, and to commit the narrative to others. (ANKERSMIT, 2001, p. $163)^{24}$

\footnotetext{
${ }^{24}$ Testemunhar diante de uma audiência de falantes ou espectadores é mais do que simplesmente relatar um fato ou um evento ou relatar o que tem sido vivido, gravado ou relembrado. A memória está evocada aqui essencialmente em ordem para endereçar a outro, para imprimir sobre um ouvinte, apelar para a comunidade... Testemunhar é então não meramente narrar, mas comprometer-se e comprometer a narrativa aos ouvintes (tradução livre do autor).
} 
Definitivamente, testemunhar está para além da descrição pura. A interferência do não vivido impede a memória de manifestar-se como outrora. Se, sob a representação, os lugares estão submetidos a contextos, significa ser a memória participativa da deliberação de motivos. Sem necessariamente adentrar no problema do trauma e do perdão, não menos importantes para a compreensão da memória, testemunhar prescinde da relação direta entre o decorrido e a lembrança. Como o decorrido constituise em informação, as lembranças não resgatam o que ocorreu, mas o representam. Esse passado recordado faz menção aos sentimentos e às sensibilidades.

Na troca de experiência da historicidade para historicidade da experiência, o que importa no evocado é sua capacidade testemunhal de comprometimento do narrador e da narrativa com o ouvinte. A experiência do passado deixa de fazer referência a contextos decorridos e passa para o uso permanente de descontextualizar e recontextualizar. Quando se trata de recordar, seu testemunho demanda contextos. Eles não perfazem um contorno definido do qual narrador e ouvinte apreendem-se, lado a lado, de frente para uma vitrine.

Em estética e memória há defesa do passado desconectado do decorrido. Neste caso, o lugar dissocia-se do tempo, eles não se reconciliam. O tempo passa para a condição de imediato e a recordação agarra-se a ele. O lugar perde seu território junto à cronologia e torna-se impressão. O lugar fica impresso sobre o testemunho, comprometimentos, verbos e advérbios; deixa de ser um para ser múltiplo, artificial e associativo.

Em relação ao bergsonismo, a teoria da representação histórica estabelece tempo e espaço a partir de uma perspectiva desafiadora. Mesmo correndo o risco de anacronismo, lugar em Ankersmit e espaço em Bergson destacam-se. Poderia mencionar ser o lugar não necessariamente para o que aconteceu, mas para a representação de significado. O lugar é artificial porque a experiência não está para historicidade e sim o contrário. O lugar não está mais submetido ao onde e quando do decorrido, mas à representação do contexto. Em contrapartida, o espaço em Bergson não possui significado, toda sua atenção é para o tempo. Então, o tempo também é velocidade e raio. 
Em Bergson, a diferença está no modo como é concebido. O espaço não pode ser significado, sua representação a partir de lugares diz do que ele não é, vazio. Tempo e lugar, para Ankersmit resolvem-se na indissociável relação mútua de determinações construídas na representação do significado. Em relação ao bergsonismo, tempo e espaço não podem ser compreendidos por essa indissociável presença no significado.

Para Bergson, existe o fatiamento do passado que não pode ser sobreposto. A base referencial para abarcar o bergsonismo na discussão estética remete a como ele concebe o fatiamento do passado. Enquanto lembrança, há necessidade de meditar na ideia de coisa; ela está entre a imagem e o objeto. A coisa passa a ser a designação para intuir mediante intervalos e intermediários.

Se há fatiamento do passado, isso implica no debate acerca da estética e da memória. Mas quando se trata de Bergson, o termo mais adequado é o de duração estética. A memória não é a duração, mas a possibilidade de compreendê-la sob o ponto de vista du dedans. Memória pode não ser duração, mas é em duração porque há um preconcebido no bergsonismo, um passado em si. Assim, não se trata do passado na condição de significado, mas no de virtual.

Ankersmit desviou-se da discussão básica em Halbwachs ${ }^{25}$ quando contestou Bergson acerca da representação simbólica. Ao mesmo tempo em que Halbwachs alarga o passado, ele o fixa sob as representações simbólicas devido a convenções sociais. Não está presente na discussão estética da memória coletiva sua determinação política, dos lugares e do estruturalismo linguístico. Incontestavelmente, no bergsonismo, o problema não se pautou por meio da memória individual, mas dos fenômenos da memória que remetem para a categoria experiência. Haveria a necessidade de problematizá-la à luz da experiência do passado.

\footnotetext{
${ }^{25}$ Em seus termos, para Bergson, o virtual seria uma espécie de retorno à percepção de outrora, ou seja, um reviver a experiência passada. Esse argumento foi sustentado porque Halbwachs pensou Bergson sob o princípio do cérebro como memória individual. Inspirado na teoria da linguagem e na psicologia de Freud, a leitura de Halbwachs desconsiderou que, para Bergson, se é possível o retorno ao passado, essa lembrança deveria ser do cérebro que se lembraria de si mesmo no momento perceptivo. Significaria, então, que o cérebro passaria a se lembrar dos instantes perceptivos. Mas, pelo contrário, o cérebro é um órgão motor, para Bergson, porque ele não possui movimento. O cérebro localiza-se no trajeto, por isso, para as pessoas, suas lembranças aparentemente permanecem as mesmas, ou seja, a percepção não consegue apreender o movimento da memória.
} 
O tempo e o espaço estão na memória-acontecimento não como complementos, oposições e anterioridade, mas coincidência e até substituição. Estritamente à questão estética e duração, não se pode mencionar que a memória está desprovida da distinção entre um passado virtual e um passado evocado. O passado responde à relação entre imediato e atualização.

Independente do sublime como manifestação não partilhada do belo, a memória convive impreterivelmente com seu acontecer, as lembranças. Se o tempo é velocidade e raio, as lembranças pontuam, pausam, orientam. O conteúdo da memória não pode ser confundido unicamente com a estética. Nesse caso, estética e duração colocam em evidência que o passado e o presente não estão distantes, há um imediato que impera, mas, a partir do bergsonismo, não se pode confundir imediato com representação. $O$ passado não está no sentimento e na sensibilidade do presente como determinismo, o que se pode conceber é que este sentimento e sensibilidade manifestam conteúdos independentes dos desejos e sensações do presente.

Não é o presente que determina o passado como memória. As associações decorridas do esforço não redundam no significado, elas perfazem o caminho do reconhecimento. E reconhecer segue o inverso do descontextualizar e recontextualizar. Há a impressão de que a memória pode ser abreviada ou prolongada pelo desejo. Bloqueio, sonegação e silêncio informam que há conteúdos e formas. As lembranças possuem autonomia em relação à vontade, mas elas não são deterministas. Bergson possui a tese do passado como sugestão podendo ser lido como passividade ou ação.

Portanto, não se pode sugerir que a discussão em relação ao passado sob o ponto de vista da estética, tanto na teoria da representação histórica quanto na metafísica imanente se esgote por fazer algumas comparações. Mesmo assim, não se pode dar por convencido que a estética seja capaz de compreender a memória como acontecimento no testemunho como privatização. Assim, há de se problematizar a ideia de contexto na memória.

Para essa finalidade, um caminho pertinente é estabelecer no centro da discussão do problema da contingência na memória e, neste caso, uma arqueologia dessa memória 
implica na discussão de questões que estão para além da estética. Raciocinar a memória como objeto motiva a questionar os limites da representação estética e epistemológica, principalmente quando se toma base no bergsonismo. Tendo a ideia de uma duração estética sob o preceito do fenômeno da memória, o estreitamento entre hermenêutica e différence possibilita recusar os excessos que estabelecem passado e memória sob os regimes da ficção e da privatização.

\section{Referências}

ANKERSMIT, Frank. Historia y tropologia: ascenso y caída de la metáfora. México: FCE, 2004, p.191-243, 315-351.

ANKERSMIT, Frank. A escrita da história: a natureza da representação histórica. Londrina, PR: Edufel, 2012, p.185-226.

ANKERSMIT, Frank. Historical representation. California, U.S.A: Stanford University Press, 2001, p.149-175.

ASSMANN, Jan. Das kulturelle gedächtnis: schrift, erinnerung und politische identität in frühen hochkulturen. München, DE: Beck, 2000, p.29-86.

BERGSON, Henri. Das gedächtnis das körpers In: HARTH, D. Die erfindung des gedächtnisses: texte, zusammengestelle und eingeleitet. Frankfurt: Keip Verlag, 1991, p.113-118.

BERGSON, Henri. Lecciones de estética y metafísica. Espanha: Siruelo, 2012, p.49-69.

BERGSON, Henri. Écrits et paroles I. France: PUF, 1957, p.129-137.

ICHIRO, Taki. Introduction à l'étude de l'esthétique bergsonienne: première formation de la notion d"'intuition". Bijutsukakenkyu (Osaka Kyoiku University, Department of Fine Arts), n.14, p.17-33, 1997. Disponível em: <https://ir.lib.osaka-kyoiku.ac.jp>. Acesso em: 08 fev. 2017.

KOSELLECK, Reinhart. Futuro passado: contribuição à semântica dos tempos históricos. Rio de Janeiro: Contraponto: Ed. PUC Rio, 2006, p.133-145.

WHITE, Hayden. Trópicos do discurso: ensaio sobre a crítica da cultura. São Paulo: EdUSP, 2001, p.65-95. 
Recebido em 04/05/2018 Aprovado em 19/06/2018

Universidade do Estado de Santa Catarina - UDESC

Programa de Pós-Graduação em História - PPGH

Revista Tempo e Argumento Volume 10 - Número 25 - Ano 2018 tempoeargumento@gmail.com 